\title{
ELABORAÇÃO DE PLANEJAMENTO ESTRATÉGICO PARA A EMPRESA RURAL
}

\author{
Winny Silva Trugilho ${ }^{1}$ \\ Bruno Fardim Christo ${ }^{2}$ \\ Gabriel Mancini Antunes da Silva ${ }^{3}$ \\ Fernanda Dassie Rangel ${ }^{4}$ \\ Elaine Cristina Gomes da Silva ${ }^{5}$
}

Resumo: A administração é uma ciência que envolve muitas áreas, uma delas é a administração estratégica, que contempla as orientações para um planejamento adequado inclusive para as empresas rurais. Desse modo permite o direcionamento de ações voltadas ao alcance de objetivos. Este estudo buscou levantar teorias acerca do planejamento estratégico e construir um modelo para a empresa rural hipotética, por meio de pesquisa classificada como exploratória, descritiva e qualitativa. Ao final pôde-se concluir que o planejamento estratégico é uma ferramenta importante para as empresas rurais. Entretanto, tais empresas podem ter dificuldades com as adaptações exigidas num planejamento estratégico.

Palavras-chave: Administração; Planejamento estratégico; Empresa.

\footnotetext{
1 Mestrado em Produção Vegetal/Universidade Estatual do Norte Fluminense Darcy Ribeiro, Brasil. E-mail: winnytrugilio@hotmail.com.

2 Agronomia/Universidade Federal do Espírito Santo, Brasil. E-mail: brunochristo@hotmail.com.

${ }^{3}$ Eng. Florestal/Universidade Federal do Espírito Santo, Brasil. E-mail: twilight.mancini@hotmail.com.

4 Eng. Química/Universidade Federal do Espírito Santo, Brasil. E-mail: fernanda.dassierangel@gmail.com.

${ }^{5}$ Ciências Florestais/Universidade Federal do Espírito Santo, Brasil. E-mail: ecristinags@gmail.com.
} 